\title{
The "incidental anesthetic" — an opportunity for the endoscopic correction of vesicoureteral reflux in children
}

\author{
Elena Tamarkina, MD; Mohammed EI-Sherbiny, MD; Roman Jednak, MD; John-Paul Capolicchio, MD, FAAP
}

See related article on page 229

\begin{abstract}
Introduction: The endoscopic management of vesicoureteral reflux (VUR) with subureteric injection (STING) has become more popular. The low morbidity associated with the STING procedure has led to some authors advocating its use as a first-line therapy. Many parents are uncomfortable with this procedure being performed in children because of the potential morbidity associated with general anesthesia. We present an alternative without added anesthetic morbidity: offering the parents a STING when their child is undergoing an anesthetic for another surgical indication.

Methods: We reviewed the records of 10 children who underwent incidental dextranomer/hyaluronic acid copolymer (DHA) injection over a 2-year period.

Results: We considered the treatment outcome after a single STING procedure to be successful in $8(80 \%)$ patients and a failure in 2 $(20 \%)$. Distribution of VUR grade, according to the highest grade per patient, was high in $5(50 \%)$ patients, moderate in $3(30 \%)$ and low in $2(20 \%)$. We observed no complications.

Conclusion: The idea of performing STING in children under incidental anesthetic introduces yet another possibility in the paradigm of VUR care. Though the long-term efficacy of DHA remains to be determined, this option reduces the potential morbidity of DHA as first-line therapy while favourably altering the cost benefit.
\end{abstract}

Can Urol Assoc J 2009;3(3):225-8

\section{Résumé}

Introduction : L'injection sub-urétérale endoscopique est une méthode de plus en plus utilisée pour la prise en charge d'un reflux vésico-urétéral (RVU). La faible morbidité associée à cette technique a amené certains auteurs à recommander son emploi en traitement de première ligne. Bien des parents ne sont pas à I'aise avec cette suggestion en raison du risque de morbidité lié à I'anesthésie générale. Nous présentons ici une solution de rechange qui n'augmente pas la morbidité liée à l'anesthésie, soit le recours à l'injection sub-urétérale endoscopique pendant que l'enfant est déjà sous anesthésie pour une autre intervention chirurgicale. Méthodes : Les dossiers de 10 enfants ayant subi une injection de copolymère de dextranomère / acide hyaluronique (DxAH) au cours d'une période de 2 ans ont été passés en revue.

Résultats : Après une seule injection sub-urétérale, l'issue du traite- ment a été jugée excellente chez 8 patients (80\%) et un échec a été constaté chez 2 patients (20\%). La distribution des stades de RVU en fonction du stade le plus élevé noté chez chaque patient était la suivante : grade élevé, 50 \%, modéré, $30 \%$ et faible, $20 \%$. Aucune complication n'a été observée.

Conclusion : L'idée de recourir à une injection sub-urétérale pendant une autre intervention nécessitant une anesthésie ajoute une option dans I'algorithme de traitement du RVU. Même si I'efficacité à long terme du DxAH reste à établir, cette option a l'avantage de réduire le risque de morbidité lié au DxAH comme traitement de première ligne tout en modifiant pour le mieux l'équation coûts-avantages.

\section{Introduction}

Commonly accepted options for the management of vesicoureteral reflux (VUR) include antibiotic prophylaxis or surgery. The endoscopic management of VUR with subureteric injection (STING) has become more popular with the availability of dextranomer/hyaluronic acid copolymer (DHA; Q-Med). In fact, the low morbidity associated with the STING procedure has led to some authors advocating its use as a first-line therapy. ${ }^{1-6}$ Many physicians are uncomfortable with this suggestion because of the potential morbidity associated with general anesthesia, especially in infants.

We present an alternative without added anesthetic morbidity: offering the parents a STING when their child is undergoing an incidental anesthetic for another surgical indication. Though the idea of combining 2 procedures under one anesthetic is not novel, the concept here is that the STING procedure would not be performed unless anesthetic was indicated for another surgery. Hence, the availability of an incidental anesthetic is paramount to the indication for surgery.

\section{Methods}

With institutional review board approval, we reviewed the records of all children who underwent an incidental STING procedure between 2004 and 2006. 
The STING technique included submucosal injection within the tunnel and suborifice injection of DHA through a 9.8 Fr offset cystoscope (WOLF). We punctured multiple sites and used multiple syringes of product as needed until adequate volcano formation was achieved. We performed a postoperative ultrasound after 1 month and a voiding cystourethrogram (VCUG) after 3 months; the children remained on antibiotic prophylaxis during that period. In cases of distal hypospadias repair, we performed the STING procedure first with the patient in a frog leg position with the buttocks elevated using padding. On completion of the STING, the nurse removed the buttocks roll from under the drapes and straightened the legs, so that the combined procedures were performed with a single preparation and drape.

\section{Results}

We identified 10 patients, all of whom were boys, for inclusion in our study. They underwent concomitant surgical procedures: orchidopexy $(n=3)$, elective circumcision $(n=2)$, MAGPI hypospadias repair $(n=2)$, repair of concealed penis $(n=1)$, diagnostic cystoscopy to rule out posterior urethral valves $(n=1)$, and meatotomy $(n=1)$ and chordee repair $(n=1)$. The mean age at the time of surgery was 2 years (range 8 mo to $5 \mathrm{yr}$, standard deviation $1.6 \mathrm{yr})$.

Vesicoureteral reflux was diagnosed after urinary tract infection (UTI) in 7 patients and was bilateral in 4 . Distribution of VUR grade by number of ureters was high (grades 4 and 5) in $3(30 \%)$ patients, moderate (grade 3 ) in $3(30 \%)$ and low (grades 1 and 2$)$ in $4(40 \%)$. Distribution of VUR grade, according to the highest grade per patient, was high in $5(50 \%)$ patients, moderate in $3(30 \%)$ and low in $2(20 \%)$ (Fig. 1). Of the 2 patients with low-grade VUR as the highest grade, none was grade 1 . Preoperative grade-1 VUR was consistently a contralateral phenomenon.

All 10 patients received a single anesthetic. We considered the treatment outcome to be successful in $8(80 \%)$ patients and a failure in $2(20 \%)$. Successful treatment outcomes included 5 patients who were free of VUR with no postoperative UTIs and 3 patients with transient, unilateral grade- 1 VUR and who were off antibiotic prophylaxis and infection-free for at least 1 year. The treatment failures included 1 patient with grade-3 VUR with duplex kidney and 1 patient with grade- 5 VUR. These 2 children remained on antibiotic prophylaxis and were not subjected to a second anesthetic for repeat STING. We observed no intraoperative or postoperative complications. The mean postoperative follow-up was 1 year (range 6 mo to $1.5 \mathrm{yr}$, standard deviation $0.3 \mathrm{yr}$ ).

\section{Discussion}

It is estimated that 50000 children in the United States receive diagnoses of VUR after UTIs each year. ${ }^{7}$ Currently, 3 management options are available: expectant management with long-term antibiotic prophylaxis, ureteral reimplantation and endoscopic treatment, which has recently increased in popularity.

Long-term antibiotic prophylaxis to prevent UTIs is generally recommended as initial therapy while waiting for spontaneous resolution. The International Reflux Study in Children ${ }^{8}$ showed a high percentage of spontaneous VUR resolution, even in patients with higher grades, but prolonged follow-up was necessary. Longterm administration of antibiotics implies the risk of bacterial resistance with promotion of breakthrough UTIs. Since prophylactic antibiotics are usually needed for years, the risk of acquired resistance is not unimportant. ${ }^{3}$ In addition, owing to the lengthy duration of therapy, compliance with treatment is often an issue. One of the additional concerns of long-term prophylaxis is the issue of adverse reactions. Sulfonamides, trimethoprim (TMP) and nitrofurantoin are most commonly prescribed for long-term prophylaxis. Most common reactions to nitrofurantoin are gastrointestinal disturbance $(4.4 / 100$ person$y r$ at risk), cutaneous reaction $(2 \%-3 \%)$, pulmonary toxicity (9 patients), hepatotoxicity (12 patients and 3 deaths), hematological toxicity (12 patients) and neurotoxicity. ${ }^{9}$ With trimethoprim/sulfamethoxazole (TMP/ SMX), the cutaneous reaction (1.4 to 7.4 events per 100 person-yr at risk), hematological toxicity $(0 \%-72 \%$ of patients) and hepatotoxicity (5 patients) were reported. ${ }^{9}$

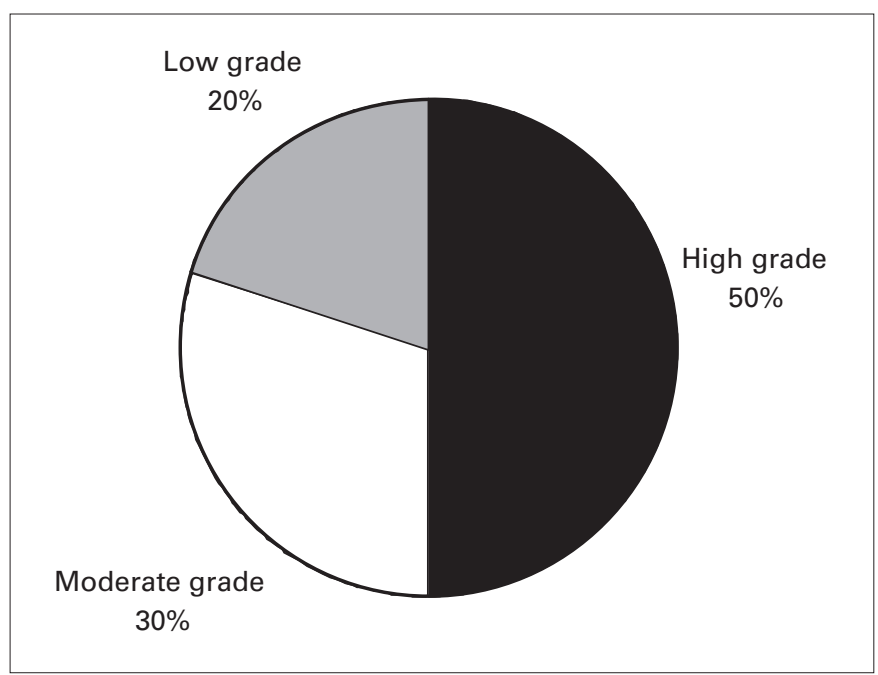

Fig. 1. Distribution of VUR grade, according to the highest grade per patient, was high in $5(50 \%)$ patients, moderate in $3(30 \%)$ and low in $2(20 \%)$. 
Photosensitization and more severe and potentially fatal reactions such as Stevens-Johnson syndrome and exfoliative dermatitis also have been reported..$^{10}$ One case report described a 3-year-old boy with suspected TMP/SMX-induced loss of fingernails and toenails. ${ }^{11}$ In addition, anaphylactic reaction associated with TMP is rare, but may be more common than previously thought. ${ }^{12}$ Although many of these adverse events are quite rare, there is no doubt that most parents are not happy with chronic antibiotic use. Another concern for parents is the increasing evidence linking antibiotic use in the first year of life with an increased risk of asthma..$^{13}$ It is not surprising that compliance with chronic antibiotic use is poor when one considers the potential adverse effects and the paucity of outcome data to alleviate those concerns.

In addition to the aforementioned problems and concerns with chronic antibiotic use, radiation exposure and especially psychological trauma from undergoing repeated VCUG are another aspect of the long-term observational approach that concerns parents. There are many hospitals in North America that practise routine oral sedation of children involved in VCUG studies. ${ }^{7}$ More over, there are hospitals that use intravenous moderate sedation in VCUG studies. Although moderate sedation was more effective at reducing psychological stress, the validity of the VCUG results may have been compromised since only $55 \%$ of participants were able to void to completion. ${ }^{14}$ The anesthetic morbidity and cost of this approach should not be ignored when compared with that of a STING procedure.

Since its introduction in 1984, endoscopic correction of VUR - the STING procedure - has proven to be a safe, effective and minimally invasive treatment for this condition. ${ }^{3}$ When compared with open surgery, the advantages of endoscopic surgery are readily apparent: it is outpatient surgery that is relatively painless, requires no convalescent period and leaves no scar. Various materials, including polytetrafluoroethylene and silicone, have been used. Concerns over safety of implant products eventually led to availability of DHA as an acceptable implant for subureteral injection for VUR in children. ${ }^{15}$ The product was approved for use in Canada in 2003, and a recent metaanalysis reported an aggregate resolution rate of $85 \% .{ }^{5}$ When compared with traditional medical treatment for grade $2-4$ VUR - antibiotic prophylaxis - one prospective study reported that $69 \%$ of patients were cured with DHA injection, compared with $38 \%$ patients in the antibiotic group. ${ }^{4}$ In addition the STING procedure has proven to be quite safe, with postoperative obstruction of the treated ureter being the only significant, yet uncommon, complication described in the literature to date. ${ }^{16-18}$ In a prospective, multi- centre study by Vandersteen and colleagues ${ }^{18}$ involving a total of 745 children (1155 ureters) who underwent DHA injections for treatment of VUR, 7 ureters $(0.6 \%)$ in 5 patients $(0.5 \%)$ exhibited postoperative obstruction, which was managed with temporary ureteral stent placement for 2-6 weeks. In all patients, symptoms resolved immediately after stent removal. ${ }^{18}$

The inherent appeal of the STING procedure, together with its safety and efficacy, has led to multiple authors advocating its use as first-line therapy in the management of VUR. ${ }^{1-6}$ One of the major disadvantages of the STING procedure compared with antibiotic prophylaxis is a need for general anesthetic during the procedure. Indeed, many parents opt for conservative treatment as first-line therapy for their children out of fear of general anesthesia. In our experience, if a child with VUR has to undergo another procedure that requires general anesthetic, parents find the idea of simultaneous STING appealing. In this situation, the riskbenefit dilemma is relatively simplified since the complication rate of the injection itself, namely obstruction of the ureter, is minimal. The additional anesthetic time required for STING is minimal. We have offered this option to the parents of children, mostly boys, undergoing general anesthetic for various urological procedures. For girls with VUR, nonurological minor procedures such as tympanostomy tubes and plastics procedures are a frequent option. Though no girls underwent surgery during this small initial experience, it is expected that, with greater knowledge of this option for treatment among families and referring physicians, this option will be possible if the urologist combines anesthesia time with other surgical colleagues.

Notwithstanding the significant advantages of STING, the procedure is not a panacea. Concerns exist over the learning curve required to obtain reliable outcomes, the cost of the procedure relative to the benefit and the potential for loss of efficacy over time..$^{19}$ Nevertheless, these limitations should not preclude its consideration as a reasonable option for treatment, ${ }^{20}$ particularly when one considers the lack of outcome data on the safety and efficacy of chronic antibiotic use. The purpose of this paper is not to validate the use of STING as first-line therapy nor to validate the results of injection therapy, but rather to introduce an idea for reducing the cost and morbidity of first-line injection therapy. We considered postoperative grade- 1 VUR to be a successful outcome if the contrast was seen in the ureter in a minority of the images obtained and if the patient remained free of infection after antibiotic prophylaxis was stopped. Though the follow-up period in our study was admittedly not long enough, our patients achieved a successful outcome by being off therapy and not experiencing any infections. 
Tamarkina et al.

\section{Conclusion}

The substantial advantages of the STING procedure make it an appealing alternative for the management of VUR, such that many authors have advocated its use as first-line therapy. Long-term outcome data and randomized clinical trials are needed to further validate the STING procedure as first-line therapy. In fact, controversy over the need to treat VUR is stronger than ever with the recognition of other confounding variables such as voiding dysfunction. Yet, in the context of informed consent, parents have the right to decide on treatment options for their children who potentially face many years of antibiotic use and unpleasant diagnostic tests. Our approach provides yet another option for parents who are interested in STING but fearful of potential anesthetic morbidity.

From the Division of Pediatric Urology, Montréal Children's Hospital, McGill University Health Centre, Montréal, Que.

This article has been peer reviewed.

Competing interests: None declared.

\section{References}

1. Kirsch A, Hensle $\mathrm{T}$, Scherz $\mathrm{H}$, et al. Injection therapy: advancing the treatment of vesicoureteral reflux. J Pediatr Urol 2006;2:539-44.

2. Elder IS, Peters $C A$, Arant $B S$, et al. Pediatric Vesicoureteral Reflux Guidelines Panel summary report on the management of primary vesicoureteral reflux in children. J Urol 1997;157:1846.

3. Puri P, Pirker M, Mohanan N, et al. Subureteral dextranomer/hyaluronic acid injections as first line treatment in the management of high grade vesicoureteral reflux. J Urol 2006;176:1856.

4. Capozza N, Caione P. Dextranomer/hyaluronic acid copolymer implantation for vesico-ureteral reflux: a randomized comparison with antibiotic prophylaxis. J Pediatr 2002;140:230.
5. Elder JS, Diaz M, Caldamone AA, et al. Endoscopic therapy for vesicoureteral reflux: a meta-analysis. I. Reflux resolution and urinary tract infection. J Urol 2006;175:716.

6. Stenberg A, Lackgren $G$. Treatment of vesicoureteral reflux in children using stabilized non-animal hyaluronic acid/dextranomer gel (NASHA/DX): A long-term observational study. J Pediatr Urol 2007;3:80.

7. Elder JS. Imaging for vesicoureteral reflux — Is there a better way? J Urol 2005;174:7.

8. Smellie JM, Jodal U, Lax H, et al.; Writing Committee, International Reflux Study in Children. (European Branch). Outcome at 10 years of severe vesicoureteral reflux managed medically: report of the International Reflux Study in Children. J Pediatr 2001;139:656.

9. Karpman E, Kurzrock EA. Adverse reactions of nitrofurantoin, trimethoprim and sulfamethoxazole in children. J Urol 2004;172:448.

10. Jick H, Derby LE. A large population-based follow-up study of trimethoprim-sulfamethoxazole, tromethoprim, and cephalexin for uncommon serious drug toxicity. Pharmacotherapy 1995;15:428.

11. Slaughenhoupt BL, Van Savage JG, Adeagbo S. A suspected case of trimethoprimsulfamethoxazoleinduced loss of fingernails and toenails. Pediatr Infect Dis J 1999;18:76.

12. Biil AM, Van der Klauw MM, Van Vliet AC, et al. Anaphylactic reactions associated with trimethoprim. Clin Exp Allergy 1998;28:510.

13. Kozyrskyi AL, Ersnt P, Becker AB. Increased risk of childhood asthma from antibiotic use in early life. Chest 2007;131:1753.

14. Merguerian PA, Corbett ST, Cravero J. Voiding ability using propofol sedation in children undergoing voiding cystourethrograms: a retrospective analysis. J Urol 2006;176:299.

15. Stenberg A, Lackgren $G$. A new bioimplant for the endoscopic treatment of vesicoureteral reflux: experimental and short-term clinical results. J Urol 1995;154:800.

16. Snodgrass WT. Obstruction of a dysmorphic ureter following dextranomer/hyaluronic acid copolymer. J Urol 2004;171:395.

17. Seifert, H-H, Mazzola B, Zellweger, T, et al.: Ureteral obstruction after dextranomer/hyaluronic acid copolymer injection for treatment of secondary vesicoureteral reflux after renal transplantation. Urology 2006;68:203.e17.

18. Vandersteen DR, Routh JC, Kirsch AJ, et al. Postoperative ureteral obstruction after subureteral injection of dextranomer/hyaluronic acid copolymer. J Urol 2006;176:1593.

19. Cendron M. Endoscopic treatment for vesicoureteral reflux: let's not get carried away! Urology 2006; 68:242.

20. Canning DA. Deflux for vesicoureteral reflux: pro - the case for endoscopic correction. Urology 2006;68:239.

Correspondence: Dr. J-P Capolicchio, Division of Urology, Montréal Children's Hospital, 2300 Tupper St., Rm. C5-27, Montréal QC H3H 1P3; fax 514 412-4384; ip.capolicchio@muhc.mcgill.ca 